\title{
Assessment of quality of life in patients with laryngeal cancer: A review of articles
}

\author{
Mateusz Kolator ${ }^{A-F}$, Patrycja Kolator ${ }^{A-F}$, Tomasz Zatoński ${ }^{A-F}$ \\ Department and Clinic of Otolaryngology Head and Neck Surgery, Jan Mikulicz-Radecki University Teaching Hospital, Wrocław, Poland \\ A - research concept and design; B - collection and/or assembly of data; C - data analysis and interpretation; \\ $D$ - writing the article; $E$ - critical revision of the article; $F$ - final approval of the article
}

\author{
Address for correspondence \\ Mateusz Kolator \\ E-mail: mateusz.kolator@gmail.com \\ Funding sources \\ None declared \\ Conflict of interest \\ None declared
}

Received on November 26, 2016

Reviewed on January 22, 2017

Accepted on March 22, 2017

\begin{abstract}
This article presents a review of the medical literature published between 1994 and 2014 with the use of the PubMed database concerning quality-of-life instruments for head and neck cancer patients used to assess general well-being of patients with laryngeal cancer. The PubMed database was searched for articles containing the keywords "quality of life", "laryngeal neoplasm" and "questionnaires". The resulting articles were reviewed and analyzed. After the identification of questionnaires, an additional search was performed. The articles and questionnaires were described and analyzed. In 43 articles, the authors used questionnaires specific to the head and neck regions in order to assess the quality of life in patients with laryngeal cancer. Four different questionnaires were identified. The European Organization for Research and Treatment of Cancer (EORTC) questionnaire is most commonly used to assess the quality of life in patients with laryngeal cancer. Questionnaires are generally used in order to select from a range of different treatment methods. There are a few head and neck cancer-related quality-of-life instruments which are widely used to assess the quality of life in patients with laryngeal cancer, but they are not dedicated to that region of the body. Today, there is much more attention paid to the quality of life; therefore, there is a real need to develop specific scales for different types of cancer.
\end{abstract}

Key words: literature review, health-related quality of life, quality of life questionnaire, head and neck neoplasms, laryngeal neoplasm

DOI

10.17219/acem/69693

\section{Copyright}

Copyright by Author(s)

This is an article distributed under the terms of the

Creative Commons Attribution Non-Commercial License

(http://creativecommons.org/licenses/by-nc-nd/4.0/) 


\section{Introduction}

The group of neoplasms called head and neck cancers (HNC) - mainly because of their location - is the $10^{\text {th }}$ most common group of cancers worldwide. They mostly begin in the squamous cells in mucosal organs in the head and neck area, such as the oral cavity, the pharynx, the larynx, the paranasal sinuses, the nasal cavity, and the salivary glands. Laryngeal cancer is the most commonly occurring neoplasm in this group. Symptoms may include a lump or sore that does not heal, a sore throat, difficulty in swallowing, and hoarseness in the voice. People who use tobacco, drink alcohol, or are exposed to the human papilloma virus are at risk of developing the disease. Treatment of laryngeal cancer because of its radical and traumatic type in every stage of the disease or therapy, i.e surgery, radiotherapy and chemotherapy, can have an effect on the quality of life even a few years later., ${ }^{1,2}$

Quality of life (QoL) is described as the quality of an individual's daily life. It is an evaluation of a person's wellbeing or lack thereof. This consists of the emotional, social, and physical aspects of a person's life. In healthcare, QoL is an assessment of how different aspects of an individual's life can be affected by a disease or a disability. Over the years, the concept of health-related QoL has evolved to encompass all aspects that can be proven to affect one's physical or mental health. Measuring QoL can deliver an enormous amount of information which has great value in modifying treatments, selecting drugs, avoiding side effects, and preventing disease. ${ }^{3}$

The aim of this study was to review the specific instruments used to assess the QoL in patients with laryngeal cancer.

\section{Description of current knowledge}

Numerous international organizations have undertaken to create instruments which would be able to accurately assess an individual's health-related QoL. There is a wide range of factors which need to be covered by this kind of questionnaire. The various tools for measuring QoL can be divided into 2 groups: general and specific. General scales assess QoL without recording the impact of the disease in particular, i.e., regardless of the pathologies. Specific scales are focused on a group of diseases, a single disease, factor, or even symptom. ${ }^{4}$

In this study, the PubMed database was searched using the MeSH keywords "quality of life", "laryngeal neoplasms" and "questionnaires" for articles published from 1990 to 2015. In total, 119 articles were found. Articles in any language other than English were not considered. Evaluation of the title and abstract excluded 76 studies, leaving 43 eligible for review. In the second search, the database was searched for properties and validations of these instruments.
Four different QoL questionnaires were identified. All questionnaires were specific to head and neck oncology, but were used for patients with laryngeal cancer. Some publications have reported the use of the European Organization for Research and Treatment of Cancer (EORTC) QLQ-C30 and H\&N modules, the University of Washington Quality of Life Questionnaire (UW-QOL v4), the Functional Assessment of Cancer Therapy for patients with head and neck cancer (FACT-H\&N), and the University of Michigan Head and Neck specific Quality of Life Instrument (HNQoL). The most widely used questionnaire is the EORTC QLQ-H\&N module, followed by the UW-QOL (Table 1).

Table 1. Usage of head and neck scales

\begin{tabular}{|l|c|}
\multicolumn{1}{|c|}{ Questionnaire } & $\begin{array}{c}\text { Citations } \\
\text { (No./\%) }\end{array}$ \\
\hline $\begin{array}{l}\text { European Organization for Research and Treatment } \\
\text { of Cancer (EORTC QLQ-H\&N) } \\
\text { University of Washington Quality of Life Questionnaire } \\
\text { (UW-QLQ v4) }\end{array}$ & $29 / 67.44$ \\
\hline $\begin{array}{l}\text { Functional Assessment of Cancer Therapy for head and } \\
\text { neck cancer (FACT-H\&N) }\end{array}$ & $3 / 6.97$ \\
\hline $\begin{array}{l}\text { University of Michigan Head and Neck specific Quality } \\
\text { of Life Instrument (HNQoL) }\end{array}$ & $1 / 2.33$ \\
\hline
\end{tabular}

There are a few studies where a specific region of the larynx (like the glottis or the hypolarynx) was assessed, but there are many more where the whole larynx as a region was taken into consideration. The authors mostly use these instruments to compare different methods of treatment. There are also a few studies where the authors have assessed voice quality, mental disorders, dysphagia, or sexual functioning (Table 2). ${ }^{5-47}$

\section{Quality of life assessment tools}

In 1994, Bjordal et al. developed the European Organization for Research and Treatment of Cancer questionnaire module to assess QoL in HNC patients. That module was specifically designed to be used before, during and after radiotherapy or surgery. The preliminary questionnaire was tested in patients from more than 5 European countries. The result was a questionnaire consisting of 37 items concerning disease- and treatment-related symptoms, social functioning and sexual functioning. ${ }^{48}$ Hammerlid et al. showed that the QLQ-C30 questionnaire was well received by patients and that the results seemed to be sensitive to changes during the one-year study. Symptoms like difficulty swallowing, hoarse voice, sore mouth, dry mouth, and problems with the sense of taste showed the greatest variability in HNC patients. ${ }^{49}$ The reliability and validity of the EORTC head and neck cancer module (QLQH\&N35) and v. 3.0 of the EORTC Core Questionnaire 
Table 2. Purposes and regions for which questionnaires were used

\begin{tabular}{|c|c|c|c|c|}
\hline Authors & Questionnaire & Region & Purpose of use & Ref. No. \\
\hline Zheng et al. & EORTC & supraglottic & swallowing assessment & 5 \\
\hline Kucuk et al. & EORTC & larynx & comparison of treatment methods & 6 \\
\hline Vilaseca et al. & UW-QLQ v4 & larynx & comparison of treatment methods & 7 \\
\hline Laoufi et al. & EORTC & glottis & voice quality assessment & 8 \\
\hline Risberg-Berlin et al. & EORTC & $\operatorname{larynx}$ & rehabilitation results assessment & 9 \\
\hline Robertson et al. & UW-QLQ v4 & larynx & $\begin{array}{c}\text { quality of life dependence on the stage } \\
\text { of tumor after treatment }\end{array}$ & 10 \\
\hline Filipovska-Mušanović et al. & EORTC & larynx/hypolarynx & comparison of treatment methods & 11 \\
\hline Kanatas et al. & UW-QLQ v4 & oral/oropharyngeal/laryngeal & quality of life assessment process & 12 \\
\hline Gilbert et al. & EORTC & $\operatorname{larynx}$ & comparison of treatment methods & 13 \\
\hline Mallis et al. & EORTC & larynx & comparison of treatment methods & 14 \\
\hline Hamid et al. & EORTC & $\operatorname{larynx}$ & comparison of treatment methods & 15 \\
\hline Azevedo et al. & UW-QLQ v4 & larynx/hypolarynx & voice quality & 16 \\
\hline Johansson et al. & EORTC & $\operatorname{larynx}$ & mental adjustment to cancer & 17 \\
\hline Danker et al. & EORTC & $\operatorname{larynx}$ & alcohol consumption assessment & 18 \\
\hline Guibert et al. & EORTC & hypopharyngeal/laryngeal & different treatment methods & 19 \\
\hline Bajaj et al. & UW-QLQ v4 & glottis & voice quality assessment & 20 \\
\hline Robertson et al. & UW-QLQ v4 & larynx & voice quality assessment & 21 \\
\hline Varghese et al. & EORTC & $\operatorname{larynx}$ & voice quality, rehabilitation results assessment & 22 \\
\hline Maclean et al. & UW-QLQ v4 & $\operatorname{larynx}$ & dysphagia assessment & 23 \\
\hline Singer et al. & EORTC & $\operatorname{larynx}$ & sexual functioning assessment & 24 \\
\hline Singer et al. & EORTC & larynx & quality of life assessment process & 25 \\
\hline Johansson et al. & EORTC & larynx & communication problems assessment & 26 \\
\hline Minovi et al. & EORTC & $\operatorname{larynx}$ & comparison of treatment methods & 27 \\
\hline Boscolo-Rizzo et al. & EORTC & $\operatorname{larynx}$ & comparison of treatment methods & 28 \\
\hline Bindewald et al. & EORTC & $\operatorname{larynx}$ & comparison of treatment methods & 29 \\
\hline Singer et al. & EORTC & $\operatorname{larynx}$ & mental disorders assessment & 30 \\
\hline Ringash et al. & FACT-H\&N & $\operatorname{larynx}$ & quality of life assessment process & 31 \\
\hline Bahannan et al. & EORTC & glottis & comparison of treatment methods & 32 \\
\hline Mowry et al. & UW-QLQ v4 & larynx/oropharynx & comparison of treatment methods & 33 \\
\hline Scalet et al. & EORTC & larynx & mental disorders assessment & 34 \\
\hline Derks et al. & EORTC & $\operatorname{larynx}$ & mental disorders assessment & 35 \\
\hline Loughran et al. & UW-QLQ v4 & glottis & different treatment methods & 36 \\
\hline Sewnaik et al. & EORTC & $\operatorname{larynx}$ & different treatment methods & 37 \\
\hline Ringash et al. & FACT-H\&N & $\operatorname{larynx}$ & quality of life assessment process & 38 \\
\hline Derks et al. & EORTC & $\operatorname{larynx}$ & comparison of treatment methods & 39 \\
\hline Muller et al. & EORTC & larynx & comparison of treatment methods & 40 \\
\hline Paleri et al. & HNQoL & $\operatorname{larynx}$ & comparison of treatment methods & 41 \\
\hline Zotti et al. & EORTC & larynx & comparison of treatment methods & 42 \\
\hline Stoeckli et al. & EORTC & $\operatorname{larynx}$ & comparison of treatment methods & 43 \\
\hline Ringash et al. & FACT-H\&N & $\operatorname{larynx}$ & comparison of treatment methods & 44 \\
\hline Allal et al. & EORTC & larynx/hypopharynx & comparison of treatment methods & 45 \\
\hline Deleyiannis et al. & UW-QLQ v4 & larynx & quality of life assessment process & 46 \\
\hline Hammerlid et al. & EORTC & larynx & comparison of treatment methods & 47 \\
\hline
\end{tabular}

EORTC - European Organization for Research and Treatment of Cancer; UW-QLQ v4 - University of Washington Quality of Life Questionnaire; FACT-H\&N - Functional Assessment of Cancer Therapy for head and neck cancer; HNQoL - Head and Neck specific Quality of Life Instrument. 
(QLQ-C30) were confirmed in studies of large groups of patients from many different countries with $\mathrm{HNC}$ in different stages of treatment. The EORTC QLQ-C30 and head and neck module (QLQ-H\&N35) demonstrates reliability and sensitivity to different groups of patients and types of treatment. ${ }^{50,51}$

The University of Washington Quality of Life Scale (UWQOL) was first published in 1993, and since then it has been developed to its current stage. It consists of 12 domains: pain, appearance, activity, recreation, swallowing, chewing, speech, shoulder, taste, saliva, mood, and anxiety; each of these are followed by an importance rating scale over the past 7 days. The third part of the questionnaire consists of 3 questions: 1 asking how patients are feeling in comparison to the month before they developed cancer, 1 question about QoL related to health and 1 about their overall QoL. ${ }^{52}$

The Functional Assessment of Cancer Therapy for Head and Neck Cancer Scale (FACT-H\&N) is one of many scales developed by the Functional Assessment of Chronic Illness Therapy (FACIT) measurement system. This questionnaire is specific to the head and neck region and consists of 5 domains; 4 of them are rather general, including "physical wellbeing", "social/family wellbeing", "emotional wellbeing", and "functional wellbeing", while the last domain is known as "additional concerns" - it strictly regards symptoms connected to the disease. The validity and reliability of this scale have also been confirmed..$^{53}$

The University of Michigan Head and Neck-Specific Quality of Life Instrument includes 20 items scored on a 5 -point rating scale: 0 - not at all, 1 - slightly, 2 - moderately, 3 - a lot, and 4 - extremely. Items are grouped into 4 domains: eating and swallowing, communication, head and neck pain, and emotional wellbeing. It also has additional optional questions $\mathrm{A}-\mathrm{G}$ which are useful for deeper insight into the patient's health and their attitudes towards the treatment. ${ }^{54}$

\section{Conclusions}

Nowadays, there is a large variability in the QoL assessment tools specific to $\mathrm{HNC}$ which have been translated and validated in many different countries and languages. However, among these, there are not many which are specific to patients with laryngeal cancer. Because of its location and functional importance, the larynx plays a critical role in the maintenance of such cardinal physiological functions as phonation, the regulation of respiratory airflow, airway protection, and swallowing. Both the laryngeal cancer itself and the impact of its treatment can affect laryngeal functions. QoL should be taken into account in the selection of treatment. It affords the possibility of choosing the treatment which has not only had the best results in clinical trials, but has also had the best effect on QoL in patients after treatment. All of the scales are similar: they concern many of the same domains, but are grouped differently. The European Organization for Research and Treatment of Cancer Quality of Life Questionnaire and the University of Washington Quality of Life Questionnaire are the most commonly used ones in the assessment of patients with laryngeal cancer, but they are not strictly specific to that neoplasm. The QLQ-C30 module in connection with QLQ-H\&N35 seem to cover most of the important aspects, but the disadvantages of this questionnaire are the large number of questions (65), the time needed to complete the questionnaire, and the complicated scoring algorithm. The UW-QOL is commonly used because of its simplicity, which makes it useful for patients. This questionnaire consists of 12 domains, but QoL in each domain is calculated on the basis of only 1 question, one which might not exactly describe the person's feelings. The FACT-H\&N is only divided into functional scales, and though it includes questions about symptoms, it is impossible to compare QoL based on symptomatic scales. The University of Michigan Head and Neck Instrument, in turn, is calculated into only 1 simple result, which does not allow QoL comparison across different domains. None of the instruments described above seem to be sensitive or specific enough to cover all the changes in the larynx's functioning caused by cancer and the impact of different types of treatment. This is confirmed by the fact that the literature describes the use of different questionnaires focused on specific symptoms, such as voice-related QoL or swallowing-related QoL, as a supplement to head and neck cancer questionnaires.

Standardization in QoL assessment and the ability to choose 1 or 2 widely used and well-known questionnaires would more readily facilitate the comparison of results from different studies in research centers around the world.

\section{References}

1. Head and Neck Cancers - National Cancer Institute. http://www. cancer.gov/types/head-and-neck/head-neck-fact-sheet. Accessed December 10, 2015.

2. Sanderson RJ, Ironside JAD. Squamous cell carcinomas of the head and neck. BMJ. 2002;325(7368):822-827.

3. CDC - Concept - HRQOL. http://www.cdc.gov/hrqol/concept.htm. Accessed December 10, 2015.

4. Heutte N, Plisson L, Lange M, Prevost V, Babin E. Quality of life tools in head and neck oncology. Eur Ann Otorhinolaryngol Head Neck Dis. 2014;131(1):33-47.

5. Zheng Y, Liu M, Li M, et al. The influence of the 'patient-to-patient model' on swallowing problems in patients with supraglottic laryngeal cancer. ORL J Otorhinolaryngol Relat Spec. 2014;76(3):171-177.

6. Kucuk H, Kurnaz SC, Kutlar G. Treatment expectations and quality of life outcomes of patients with laryngeal cancer based on different treatment methods. Eur Arch Otorhinolaryngol. 2015;272(5):1245-1250.

7. Vilaseca I, Bernal-Sprekelsen M, Him R, Mandry A, Lehrer E, Blanch JL. Prognostic factors of quality of life after transoral laser microsurgery for laryngeal cancer. Eur Arch Otorhinolaryngol. 2015;272(5):1203-1210.

8. Laoufi S, Mirghani H, Janot F, Hartl DM. Voice quality after treatment of T1a glottic cancer. Laryngoscope. 2014;124:1398-1401.

9. Risberg-Berlin B, Karlsson TR, Tuomi L, Finizia C. Effectiveness of olfactory rehabilitation according to a structured protocol with potential of regaining pre-operative levels in laryngectomy patients using nasal airflow-inducing manoeuvre. Eur Arch Otorhinolaryngol. 2014;271(5):1113-1119. 
10. Robertson SM, Yeo JCL, Sabey L, Young D, MacKenzie K. Effects of tumor staging and treatment modality on functional outcome and quality of life after treatment for laryngeal cancer. Head Neck. 2013;35(12):1759-1763.

11. Filipovska-Mušanović $M$, Hodžić $D$, Hrnčić $N$, Hatibović $H$. Quality of life in patients with larygeal/hypopharyngeal cancer following total/partial laryngectomy. Med Glas (Zenica). 2012;9(2):287-292.

12. Kanatas A, Ghazali N, Lowe D, et al. Issues patients would like to discuss at their review consultation: Variation by early and late stage oral, oropharyngeal and laryngeal subsites. Eur Arch Otorhinolaryngol. 2013;270(3):1067-1074.

13. Gilbert RW, Goldstein DP, Guillemaud JP, Patel RS, Higgins KM, Enepekides DJ. Vertical partial laryngectomy with temporoparietal free flap reconstruction for recurrent laryngeal squamous cell carcinoma: Technique and long-term outcomes. Arch Otolaryngol Head Neck Surg. 2012;138(5):484-491.

14. Mallis A, Goumas PD, Mastronikolis NS, et al. Factors influencing quality of life after total laryngectomy: A study of 92 patients. Eur Rev Med Pharmacol Sci. 2011;15(8):937-942.

15. Hamid OA, El Fiky LM, Medani MM, Abdelhady A, Ali HH. Laryngeal cancer in Egypt: Quality of life measurement with different treatment modalities. Head Neck. 2011;33:1162-1169.

16. Azevedo EHM, Montoni N, Gonçalves Filho J, Kowalski LP, Carrara-de Angelis $\mathrm{E}$. Vocal handicap and quality of life after treatment of advanced squamous carcinoma of the larynx and/or hypopharynx. J Voice. 2012;26:e63-71.

17. Johansson $M$, Rydén A, Finizia C. Mental adjustment to cancer and its relation to anxiety, depression, $\mathrm{HRQL}$ and survival in patients with laryngeal cancer - A longitudinal study. BMC Cancer. 2011;11:283.

18. Danker H, Keszte J, Singer S, et al. Alcohol consumption after laryngectomy. Clin Otolaryngol. 2011;36:336-344.

19. Guibert M, Lepage B, Woisard V, Rives M, Serrano E, Vergez S. Quality of life in patients treated for advanced hypopharyngeal or laryngeal cancer. Eur Ann Otorhinolaryngol Head Neck Dis. 2011;128(5):218-223.

20. Bajaj Y, Uppal S, Sharma RK, et al. Evaluation of voice and quality of life after transoral endoscopic laser resection of early glottic carcinoma. J Laryngol Otol. 2011;125(7):706-713.

21. Robertson SM, Yeo JCL, Dunnet C, Young D, MacKenzie K. Voice, swallowing, and quality of life after total laryngectomy - Results of the west of Scotland laryngectomy audit. Head Neck. 2012;34:59-65.

22. Varghese BT, Mathew A, Sebastian P, lype EM, Vijay A. Comparison of quality of life between voice rehabilitated and nonrehabilitated laryngectomies in a developing world community. Acta Otolaryngol. 2011;131(3):310-315.

23. Maclean J, Cotton S, Perry A. Dysphagia following a total laryngectomy: The effect on quality of life, functioning, and psychological well-being. Dysphagia. 2009;24:314-321.

24. Singer S, Danker H, Dietz A, et al. Sexual problems after total or partial laryngectomy. Laryngoscope. 2008;118:2218-2224.

25. Singer S, Wollbrück D, Wulke $C$, et al. Validation of the EORTC QLQ-C30 and EORTC QLQ-H\&N35 in patients with laryngeal cancer after surgery. Head Neck. 2009;31(1):64-76.

26. Johansson M, Rydén A, Finizia C. Self evaluation of communication experiences after laryngeal cancer - A longitudinal questionnaire study in patients with laryngeal cancer. BMC Cancer. 2008;8:80.

27. Minovi A, Ural A, Nowak C, Pearson M, Dazert S, Brors D. Long-term quality of life evaluation after laser microsurgery with or without adjuvant radiotherapy for laryngeal carcinoma. Kulak Burun Bogaz Ihtis Derg. 2008;18(6):362-366.

28. Boscolo-Rizzo P, Maronato F, Marchiori C, Gava A, Da Mosto MC. Long-term quality of life after total laryngectomy and postoperative radiotherapy versus concurrent chemoradiotherapy for laryngeal preservation. Laryngoscope. 2008;118:300-306.

29. Bindewald J, Oeken J, Wollbrueck D, et al. Quality of life correlates after surgery for laryngeal carcinoma. Laryngoscope. 2007;117:1770-1776.

30. Singer S, Danker $H$, Dietz A, et al. Screening for mental disorders in laryngeal cancer patients: A comparison of 6 methods. Psychooncology. 2008;17:280-286.

31. Ringash J, O'Sullivan B, Bezjak A, Redelmeier DA. Interpreting clinically significant changes in patient-reported outcomes. Cancer. 2007;110:196-202.

32. Bahannan AA, Zábrodsky M, Cerny L, Chovanec M, Lohynska R. Quality of life following endoscopic resection or radio-therapy for early glottic cancer. Saudi Med J. 2007;28:598-602.
33. Mowry S, Lotempio M, Sadeghi A, Wang K, Wang M. Quality of life outcomes in laryngeal and oropharyngeal cancer patients after chemoradiation. Otolaryngol Head Neck Surg. 2005;132(6):948-953.

34. Scalet D, Braz A, Ribas MM, et al. Quality of life and depression in patients undergoing total and partial laryngectomy. Clinics. 2005;60:135-142.

35. Derks W, Leeuw JRJ, Hordijk GJ, Winnubst JAM. Differences in coping style and locus of control between older and younger patients with head and neck cancer. Clin Otolaryngol. 2005;30:186-192.

36. Loughran S, Calder N, MacGregor FB, Carding P, MacKenzie K. Quality of life and voice following endoscopic resection or radiotherapy for early glottic cancer. Clin Otolaryngol. 2005;30:42-47.

37. Sewnaik A, Van Den Brink JL, Wieringa MH, Meeuwis CA, Kerrebijn JDF. Surgery for recurrent laryngeal carcinoma after radiotherapy: Partial laryngectomy or total laryngectomy for a better quality of life? Otolaryngol Head Neck Surg. 2005;132:95-98.

38. Ringash J, Bezjak A, O'Sullivan B, Redelmeier DA. Interpreting differences in quality of life: The FACT-H\&N in laryngeal cancer patients. Qual Life Res. 2004;13(4):725-733.

39. Derks W, Leeuw JRJ, Hordijk GJ, Winnubst JAM. Reasons for nonstandard treatment in elderly patients with advanced head and neck cancer. Eur Arch Otorhinolaryngol. 2005;262(1):21-26.

40. Müller R, Paneff J, Köllner V, Koch R. Quality of life of patients with laryngeal carcinoma: A post-treatment study. Eur Arch Otorhinolaryngol. 2001;258:276-280.

41. Paleri V, Stafford FW, Leontsinis TG, Hildreth AJ. Quality of life in laryngectomees: A post-treatment comparison of laryngectomy alone versus combined therapy. J Laryngol Otol. 2001;115:450-454.

42. Zotti P, Lugli D, Vaccher E, Vidotto G, Franchin G, Barzan L. The EORTC quality of life questionnaire-head and neck 35 in Italian laryngectomized patients. European organization for research and treatment of cancer. Qual Life Res. 2000;9:1147-1153.

43. Stoeckli SJ, Guidicelli M, Schneider A, Huber A, Schmid S. Quality of life after treatment for early laryngeal carcinoma. Eur Arch Otorhinolaryngol. 2001;258:96-99.

44. Ringash J, Redelmeier DA, O'Sullivan B, et al. Quality of life and utility in irradiated laryngeal cancer patients. Int J Radiat Oncol.2000;47:875-881.

45. Allal AS, Dulguerov P, Bieri S, Lehmann W, Kurtz JM. Assessment of quality of life in patients treated with accelerated radiotherapy for laryngeal and hypopharyngeal carcinomas. Head Neck. 2000;22:288-293.

46. Deleyiannis FW, Weymuller EA, Coltrera MD, Futran N. Quality of life after laryngectomy: Are functional disabilities important? Head Neck. 1999;21:319-324.

47. Hammerlid E, Mercke C, Sullivan M, Westin T. A prospective quality of life study of patients with laryngeal carcinoma by tumor stage and different radiation therapy schedules. Laryngoscope. 1998;108:747-759.

48. Bjordal K, Ahlner-Elmqvist M, Tollesson E, et al.; EORTC Quality of Life Study Group. Development of a European Organization for Research and Treatment of Cancer (EORTC) questionnaire module to be used in quality of life assessments in head and neck cancer patients. Acta Oncol. 1994;33:879-885.

49. Hammerlid E, Bjordal K, Ahlnerelmqvist $M$, et al. Prospective, longitudinal quality-of-life study of patients with head and neck cancer: A feasibility study including the EORTC QLQ-C30. Otolaryngol Head Neck Surg. 1997;116(6 Pt 1):666-673.

50. Sherman AC, Simonton S, Adams DC, Vural E, Owens B, Hanna E. Assessing quality of life in patients with head and neck cancer. Arch Otolaryngol Neck Surg. 2000;126:459.

51. Bjordal K, de Graeff A, Fayers $P$, et al. A 12 country field study of the EORTC QLQ-C30 (version 3.0) and the head and neck cancer specific module (EORTC QLQ-H\&N35) in head and neck patients. EORTC Quality of Life Group. Eur J Cancer. 2000;36(14):1796-1807.

52. Rogers SN, Lowe D. The University of Washington Quality of Life Scale. In: Handbook of Disease Burdens and Quality of Life Measures. New York, NY: Springer New York; 2010:101-128.

53. List MA, D'Antonio LL, Cella DF, et al. The performance status scale for head and neck cancer patients and the functional assessment of cancer therapy-head and neck scale: A study of utility and validity. Cancer. 1996;77:2294-2301.

54. Ronis DL, Fowler KE, Bradford CR, et al. Clinical predictors of quality of life in patients with head and neck cancer. Arch Otolaryngol Head Neck Surg. 2004;130(4):401-408. 